\title{
PROMOÇÃO DA SAÚDE MENTAL DOS IDOSOS NO PROGRAMA QUARENTENA - NÚCLEO DE ESTUDOS DA TERCEIRA IDADE
}

Maria Fernanda Baeta Neves Alonso da Costa; Universidade Federal de Santa Catarina; fernanda.baeta@gmail.com

Michele Medeiros; Universidade Federal de Santa Catarina; mtmedeiro@gmail.com Geovana Samuel Oliveira; Universidade Federal de Santa Catarina; contatogeovanaoliveira@gmail.com

\section{RESUMO}

Introdução: A pandemia pelo COVID-19 é um fenômeno mundial e tem acarretado alterações físicas e disfunções psíquicas nos indivíduos. Devido aos impactos causados pelo isolamento social são necessárias estratégias para o cuidado psíquico e a manutenção de uma rede socioafetiva com familiares, amigos e profissionais da saúde. A utilização de redes sociais digitais auxiliam o idoso a não se sentir isolado do mundo exterior e devem ser utilizadas a fim de explicar o processo de quarentena diminuir os impactos psicológicos no distanciamento social (LIMA et al, 2020). O Programa Quarentena no Núcleo de Estudos da Terceira Idade (NETI) foi proposto com o objetivo de manter o vínculo com os alunos idosos, no período de isolamento social e promover a saúde mental durante a pandemia. Objetivo: Descrever a influência do Programa na saúde mental dos alunos idosos do NETI durante a pandemia. Método: Relato de experiência sobre o uso de aplicativo de mensagens, whatsApp, para envio de materiais informativos que, são enviados duas vezes na semana para os alunos idosos matriculados nas atividades socioeducativas, no período de suspensão das aulas presenciais. Resultados: A utilização do aplicativo e a disponibilização de informações tem proporcionado o vínculo com os alunos idosos e promovido a saúde mental, no período da quarentena por meio da informação e comunicação. Conclusão: A viabilização de informações relevantes via aplicativo tem repercutido de forma positiva na manutenção do vínculo social assim como na melhoria da saúde mental dos alunos idosos do NETI.

Palavras-chave: Idoso; Saúde Mental; Pandemia. 